\title{
Simulation Experiment on Gas Flow Patterns \\ in a Reheating Furnace*
}

\author{
By Syōgo MATSUNAGA** and Bunsho HIRAOKA**
}

\begin{abstract}
Synopsis
Many simulation techniques have been applied to the iron and steel making processes; fluid flow models have been especially helpful for investigating the gas flow in furnaces.

The reconstruction of a three-zone pusher furnace was planned to increase its heating capacity. Enlargement of the combustion space was to be achieved by raising the furnace roof and this made it necessary to find the most suitable position and orientation of burners in each zone. In addition, the roof height at the nose of the soaking zone and the preheating zone and the effect on the gas flow in the case of the piling up of scale were also to be considered. The gas flow patterns in the furnace were examined under a variety of conditions. The tests were arranged to establish the most desirable design of the furnace with regard to the roof shape and the burner setting. They enabled the furnace to be reconstructed satisfactorily.
\end{abstract}

\section{Introduction}

A reheating furnace is a device for heating steel slabs or billets to the required temperature for rolling; its capacity must therefore be balanced with that of the rolling mill. Owing to the recent rapid development of the iron and steel making processes, it is indispensable at the present time to give the solutions of several problems concerning the reheating furnace such as increasing its heating capacity, strict control of the temperature distribution of the metal, low consumption of fuel, high durability of the furnace, and so on. The solutions of some of these problems may be given by the use of a suitable model. Practical solutions for the design of the furnace construction or the operation condition are easily found by this technique. In this paper a model analysis for the reconstruction of a three-zone pusher furnace is discussed to get a higher heating capacity.

\section{General View of Model Experiments}

Simulation analysis includes various kinds of techniques, such as mathematical, geometrical, dynamical, thermal, electrical, optical, and so on. Basic theories related to these techniques have already been discussed by several authors. ${ }^{1)}$ In this paper the gas flow patterns in a three-zone pusher furnace are investigated by means of a fluid dynamics model. Similarity criteria for fluid dynamics models are already established and well summarized.2) This sort of analysis using a hydrodynamic or an aerodynamic model has been widely applied. The method is applicable to a number of processes concerned in iron and steel making. ${ }^{3-5)} \quad$ For instance, in the field of iron making process, gas flow patterns in blast furnaces ${ }^{6)}$ and hot stoves $^{7,8)}$ or water models of blast furnace tuyeres ${ }^{9)}$ have been investigated. In the field of steel making process, there are many excellent experiments concerning open hearth furnaces ${ }^{10)}$ and the recent developments of the LD converter have made the use of this kind of analysis with respect to the behaviour of the oxygen jet, gas flow, and molten metal flow as well. ${ }^{11)}$ In addition, similar analyses have been accomplished on a desulphurizing furnace, ${ }^{12)}$ mixing furnace for molten iron ${ }^{13)}$ or splashing behaviour in pouring the molten steel into ingot cases. ${ }^{14,15)}$ With regard to subsequent processes, many gas flow pattern analyses have been made for soaking pits, ${ }^{8,16,17)}$ pusher type reheating furnaces, ${ }^{18)}$ and rotary hearth furnaces. ${ }^{19)}$

The method is specially effective when the design or the construction of a new equipment is considered and also when the reconstruction of an existing equipment is necessitated.

When the flow patterns are investigated, the criteria of geometric and the fluid dynamic similarity must be satisfied. In general the geometric similarity is satisfied by the use of a scaled model of the prototype. However, it is sometimes difficult when the details in the prototype such as the surface roughness, errosion of the brick work, and the effect of piled up scale can not be accurately estimated. These effects are usually unimportant. Occasionally it may be desirable to depart from the strict geometric similarity, for instance, in the case of modelling non-isothermal jets or flame system, which is known as the Thring-Newby criterion.

Fluid dynamics criteria may be developed from the Navier-Stokes' equation for the prototype and the model. For example, it may be shown that the Reynold's Number $(R e)$ is the important criterion when the ratio of viscous to inertial forces dominates the system, and that the Faoude's Number becomes effective when the ratio of gravitational to inertial forces dominates. If the effects of surface tension contribute largely to the system, the Weber's Number has a meaning and so on. Fortunately the latter arises but rarely in the problems of interest to the steel industry, since it becomes increasingly difficult to satisfy these criteria as their total number increases. When difficulties arise in trying to satisfy the conflicting requirements, a solution may be found if they can be established the forces in the system which are the most effective and thus establishing the most suitable similarity criterion to be adopted. It is an established fact that when the value of $R e$ is high enough to lie in the turbulent region, the flow patterns remain relatively unchanged, so that at high Reynold's Number strict parity of $R e$ is

\footnotetext{
* Originally published in Tetsu-to-Hagané, 56 (1970), 1575, in Japanese. English version received May 11, 1971.
}

** Central Research Laboratory, Sumitomo Metal Industries, Ltd., Nishinagasu-Hondori, Amagasaki 660. 
unnecessary.

\section{Model Experiments}

\section{The Prototype and the Model}

The furnace forming the basis of this experiment is a three-zone pusher type reheating furnace, the heating capacity of which is about $40 \mathrm{t} / \mathrm{hr}$, used for heating steel ingots or blooms whose thickness is 270 to $450 \mathrm{~mm}$. The reconstruction of this furnace was planned because of the shortage of its heating capacity. When the reconstruction of an existing furnace is planned, it is usually very difficult to change the design of the lower combustion chamber or the total furnace length because of the limited space. In this case the furnace had already been equipped with side burners in its preheating zone. The main reconstruction contemplated was to be the raising of the furnace roof by $200 \mathrm{~mm}$ to make the combustion space larger by $20 \%$. Figure 1 shows some characteristic dimensions of the furnace.

The model furnace was constructed with transparent acrylic resin; the scale down ratio was $1 / 30$. The model included only the half width of the furnace because of its axial symmetry and semi-three-dimensional flow was obtained.

\section{Contents and the Experimental Method}

As already mentioned, the basic idea of reconstruction was to raise the roof by $200 \mathrm{~mm}$. The main purpose of the model was to determine the burner direction and its setting and also the roof heights at the nose of the soaking zone and the preheating zone. These latter are of importance in relation to the pressure inside the furnace at the soaking zone which determines, in turn, the quantity of cold air which leaks into the furnace from the discharging door. Whatever the aerodynamic requirements were, any changes in the furnace design suggested by the model experiments would need to lie compatible with the modified heat transfer requirements. The heat transfer in the furnace consists of furnace wall radiation, gas radiation and forced convection heat transfer and the total quantity of heat transfer should be more than that before the reconstruction. In addition the model was also used to assess the effect of piling up of scale which occurs after a long continuous operation of the furnace. Table 1 shows the combustion space before and after the reconstruction. The increase in the volume of the lower heating zone is due to the use of plastic fireclay instead of fire brick which made it possible to make the side wall thinner.

The flow rate in the model was decided by both of the normal operation characteristics of the prototype furnace and the Re criterion. The ratio of flow rate in each zone was kept to the same as the original one and the minimum flow rate was so decided that the value of $R e$ would exceed 2300 , which is the lowest limit of $R e$ to lie in the turbulent region. The values of these experimental conditions are shown in Table 2.

The fluid used in the model experiments was water in which pulverized aluminium was suspended as the tracer. ${ }^{20)}$ Aluminium powder (100 to $200 \mu$ ) was added to water in a tank and well stirred. This water was pumped to the furnace model through flow meters which enabled water flow rate to be regulated. The model was set up in a dark room and a slit light was projected onto it and thus the flow lines were visualized. Flow patterns were recorded by both photographic means and sketches. The longitudinal sectional planes investigated were those of burner axis, between burners and near the side wall.

Table 1. Combustion space before and after reconstruction

\begin{tabular}{|c|c|c|c|}
\hline Zone & $\begin{array}{l}\text { Before } \\
\text { recon- } \\
\text { struction }\end{array}$ & $\begin{array}{l}\text { After } \\
\text { recon- } \\
\text { struction }\end{array}$ & $\begin{array}{c}\text { Ratio } \\
(\%)\end{array}$ \\
\hline Soaking zone & $51.6 \mathrm{~m}^{3}$ & 57.6 & 112 \\
\hline Upper heating zone & $112.5 \mathrm{~m}^{3}$ & 152.5 & 136 \\
\hline Lower heating zone & $122.3 \mathrm{~m}^{3}$ & 128.1 & 105 \\
\hline Total & $286.4 \mathrm{~m}^{3}$ & 338.2 & 118 \\
\hline Heating capacity & $37 \mathrm{t} / \mathrm{hr}$ & $43 \mathrm{t} / \mathrm{hr}$ & 116 \\
\hline
\end{tabular}

Table 2. Experimental conditions

\begin{tabular}{l|cc} 
& Flow rate $(1 / \mathrm{min})$ & $R e$ \\
\hline Soaking zone & 1 & $3.09 \times 10^{3}$ \\
Upper heating zone & 5 & $7.71 \times 10^{3}$ \\
Lower heating zone & 5 & $6.97 \times 10^{3}$
\end{tabular}

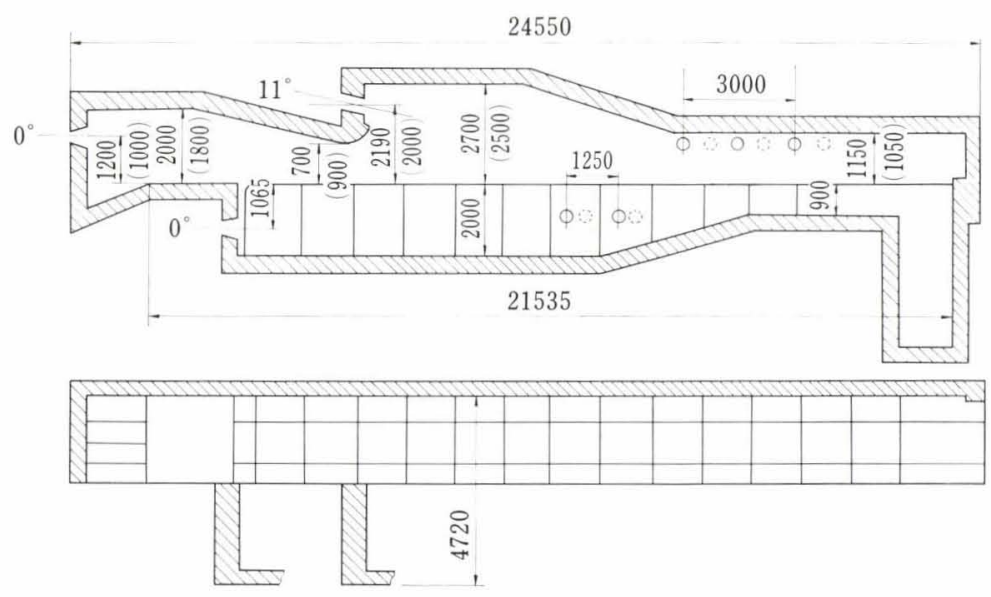

Fig. 1. Dimensions of the reconstructed furnace 


\section{Experimental Results and Discussion}

\section{Gas Flow Pattern in the Furnace before Reconstruction}

Gas flow patterns in the furnace were investigated for several conditions. Figure 2 shows the gas flow patterns of three sections in the furnace before the reconstruction. On the section at the burner axis the flow pattern is decided by the furnace shape and the direction of the burner jet. In the soaking zone the burner jet impinges on the roof and then flows according to the roof shape. At the nose of the soaking zone the height between the roof and the material is such that some of the combustion gas flows back towards the burner wall on the surface of the material. At the top of the burner wall the gas flow is also reversed owing to the entrainment by the burner jet and forms a recirculating flow. This entrainment recirculation is also observed under the burner jet. In the upper heating zone the burner jet impinges directly on the stock and flows forward to the exit port over the surface of the material being heated. A part of the combustion gas returns to the burner wall above the burner jet and forms a recirculating flow in the space between the burner jet and the roof. The combustion gas from the soaking zone is entrained into the main jet. In the lower heating zone the burner jet flows slightly upwards and passes to the exit port. On the bottom of the lower heating zone there exists a reversed flow owing to the jet entrainment and the shape of the furnace.

On the section between burners the gas flow pattern is almost the same as that of burner axis. On the section near the wall, there is no strong flow and the flow pattern is rather complicated. In the soaking zone some of the combustion gas flows back to the burner wall owing to the burner jet entrainment and most of it travels forward and mixes into the lower heating zone. Some of the combustion gas in the lower heating zone rises upward along the burner wall and returns to the soaking zone. In the upper heating zone the clear recirculation flow is again observed. The lower part of this recirculation gas flows to the exit port together with the gas from the lower heating zone. In the lower heating zone the reversed flow at the bottom

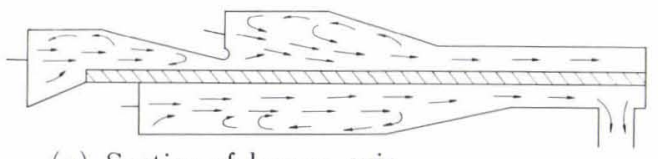

(a) Section of burner axis

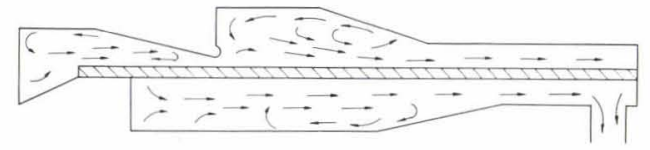

(b) Section between burners

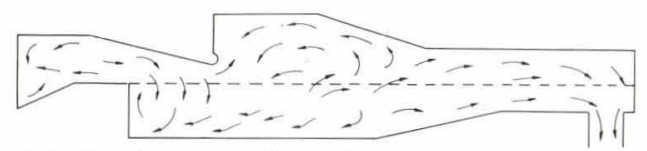

(c) Section near the wall

Fig. 2. Gas flow patterns in the furnace before reconstruction is also rather strong but after the middle of the zone the gas flows directly to the exit port.

By using ingot and bloom size model material, it was shown that the size of the heating material did not play an important role.

\section{Burner Setting in the Soaking Zone}

Three cases were investigated in which the burner position was raised by 210 or $300 \mathrm{~mm}$ keeping the horizontal direction and raised by $300 \mathrm{~mm}$ with the downward direction of $5^{\circ}$. The gas flow patterns in these cases are shown in Fig. 3.

When the burner is raised by $300 \mathrm{~mm}$ horizontally, the recirculation flow just below the roof becomes very small. The burner jet impinges on the roof directly and flows along the roof. In the prototype this would cause a local overheating of the roof firebrick. On the other hand, the recirculation flow below the jet becomes larger and the gas flows towards the burner wall over the surface of the stock.

The other two cases have similar flow patterns which are in appearance between the original case and the above mentioned case. These changes of the burner setting do not have any effect on the gas flow pattern of the upper or the lower heating zone.

The last two cases give the best pattern. In practice the burner was raised by $200 \mathrm{~mm}$ and was maintained horizontally. This is also better arrangement for the piling up of scale, a condition which is mentioned later.

\section{Burner Setting in the Upper Heating Zone}

Seven cases were investigated in which the burner height and its direction were varied and these results are shown in Fig. 4.

When the burner was lowered by $180 \mathrm{~mm}$ with the downward direction of $0^{\circ}$ or $5^{\circ}$, the burner jet is too low and naturally the recirculation flow above the jet grows larger. In these cases flame impinges on the material directly and this in practice would cause a local overheating of the material. This design does not make for a good relationship of the burner and the combustion space. It is important for flame not to impinge on the roof or the material directly.

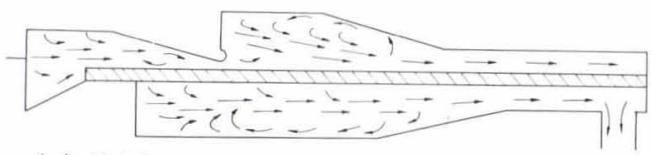

(a) Height: $1200 \mathrm{~mm}$, Direction:0

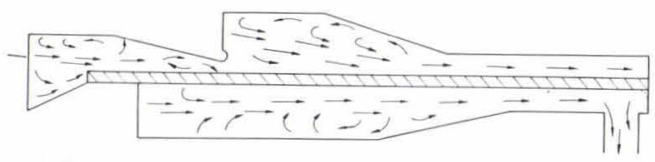

(b) Height : $1310 \mathrm{~mm}$, Direction: $5^{\circ}$ downwards

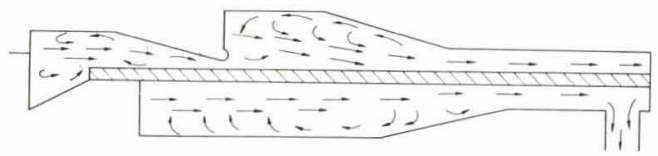

(c) Height: $1310 \mathrm{~mm}$, Direction: $0^{\circ}$

Fig. 3. The effect on gas flow patterns in the soaking zone of burner setting. (Section of burner axis) 
When the burner is kept at the same height as the original one, it is better to have a gentle angle of $5^{\circ}$. In this case the flow pattern is not so bad. But if the angle is too small, i.e., $0^{\circ}$, the burner jet impinges on the roof, which is not acceptable.

When the burner is raised by $200 \mathrm{~mm}$, the burner direction of $11^{\circ}$ gives the best flow pattern. A smaller inclination is not so good from the same reason as mentioned above. In this case the most desirable flow pattern is obtained by raising the burner up or by making the inclination small, which this concept is also applicable to the soaking zone.

\section{Burner Setting in the Lower Heating Zone}

Gas flow patterns for several conditions are shown in Fig. 5. The burner of the lower heating zone is set at a rather high position. If the burner is lowered by $575 \mathrm{~mm}$, the burner jet flows along the bottom of the furnace and the gas recirculates just below the material. This height is equal to $360 \mathrm{~mm}$ from the bottom of the furnace and it may cause some difficulties because of the piling up of scale during a long run operation of the furnace. Moreover the gas flow pattern is not generally good. If the burner is directed upward by $5^{\circ}$, then the flow pattern becomes fairly good but it still has the same poor characteristics as mentioned before. The burner should be so arranged not to cause difficulties in a long run operation of the furnace.

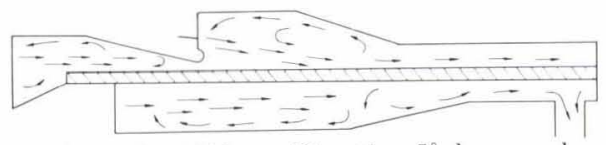

(a) Height : $1800 \mathrm{~mm}$, Direction: $5^{\circ}$ downwards

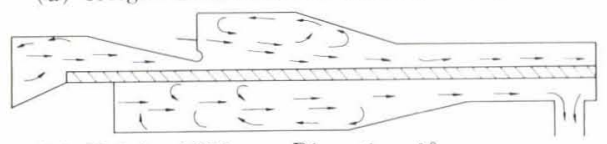

(b) Height: $1800 \mathrm{~mm}$, Direction: 0

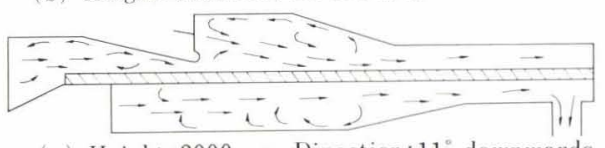

(c) Height : $2000 \mathrm{~mm}$, Direction: $11^{\circ}$ downwards

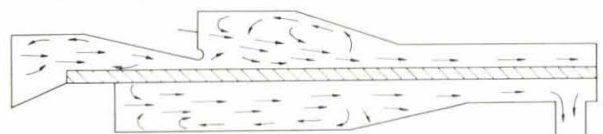

(d) Height:2000 mm, Direction: $5^{\circ}$ downwards

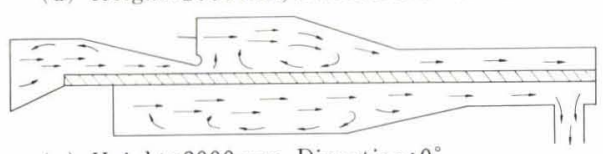

(e) Height: $2000 \mathrm{~mm}$, Direction: $0^{\circ}$

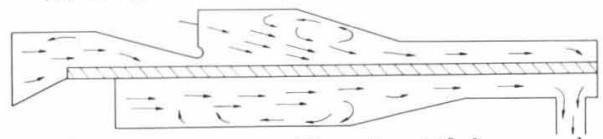

(f) Height: $2190 \mathrm{~mm}$, Direction: $11^{\circ}$ downwards

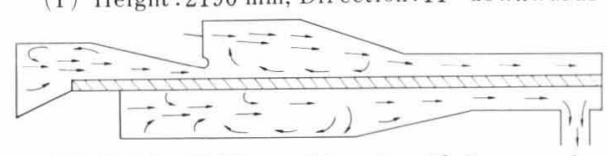

(g) Height: $2190 \mathrm{~mm}$, Direction : $5^{\circ}$ downwards

Fig. 4. The effect of burner setting on the gas flow patterns in the upper heating zones. (Section of burner axis)
When the burner is raised by $300 \mathrm{~mm}$ from this height, the burner jet still flows along the bottom of the furnace and there is a recirculation below the material. If the burner is directed upward by $5^{\circ}$ at the same height, the burner jet flows along the lower surface of the material and the gas also recirculates at the bottom of the furnace. This flow pattern is not so bad but almost the same as the present construction. Accordingly the present burner setting is the best in the lower heating zone because this can be operated even if scale has piled up.

\section{Roof Height at the Nose of Soaking Zone}

In the soaking zone when the discharging door is opened, cold air comes into the furnace if the pressure inside the furnace is not high enough. This gives rise to excess oxygen in the soaking zone and reduces the temperatures of the furnace and of the edge of the material and also produces scale. In order to avoid this the pressure inside the furnace at the soaking zone should be maintained at a higher level. One of the devices to make this possible is lowering the roof height at the nose. Figure 6 shows the gas flow pattern which is obtained when this is done. Now the exit from the soaking zone is so narrow that a smaller quantity of the gas goes to the upper heating zone.

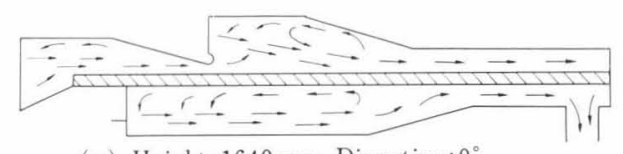

(a) Height: $1640 \mathrm{~mm}$, Direction: $0^{\circ}$

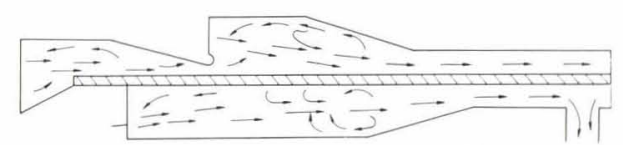

(b) Height : $1640 \mathrm{~mm}$, Direction: $5^{\circ}$ upwards

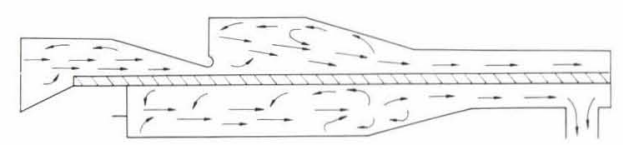

(c) Height: $1340 \mathrm{~mm}$, Direction: $0^{\circ}$

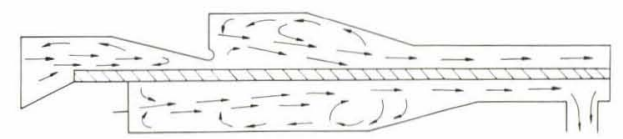

(d) Height : $1340 \mathrm{~mm}$, Direction: $5^{\circ}$ upwards

Fig. 5. The effect of burner setting on the gas flow patterns in the lower heating zone. (Section of burner axis)

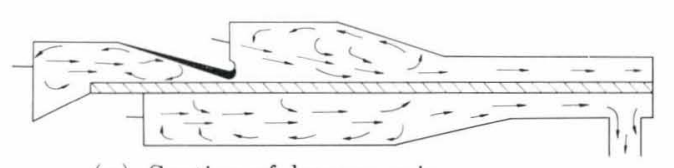

(a) Section of burner axis

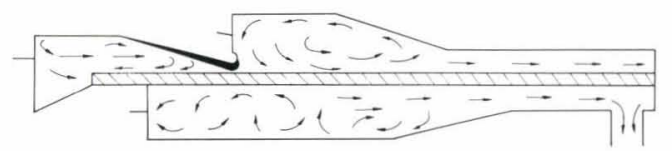

(b) Section between burners

Fig. 6. Gas flow patterns when the nose of soaking zone is lowered. (Section of burner axis) 
When the material is thick, this tendency becomes much stronger and instead there is a greater tendency for the combustion gases to go to the lower heating zone through the space between the side wall and the material.

But this device is not enough to stop the leakage of cold air. It is important to raise the pressure in the soaking zone but this depends not only on the roof height at the nose but also on the space between the side wall and the material and the position of the burner wall of the lower heating zone. For instance if the burner wall should be moved to the bottom of the soaking zone in order to increase the lower combustion space, the combustion gas of the soaking zone would go to the lower heating zone and make it difficult to maintain a high pressure in the soaking zone. The lower roof at the nose, however, has some advantages for this purpose.

\section{Roof Height at the Preheating Zone}

The gas flow pattern is very simple in the preheating zone, namely gases are just flowing towards the gas port and the velocity depends upon the height of the roof. The higher the roof is, the smaller the velocity becomes. In this zone it is important to know the relation between the roof height and the rate of heat transfer. Heat is transferred from the wall and the roof by radiation, particularly by the gas radiation and the forced convection. When the roof is low, the effective thickness of the combustion gases becomes small and the gas radiation will be less but the gas velocity becomes high and the forced convection will be more. The change in the solid radiation is very small since the side wall has but a little change in its surface area. The roof height should be decided by the rate of heat transfer because the gas flow patterns are almost the same in both cases and also do not have any effect on the gas flow patterns in the other parts of the furnace.

\section{Piling Up of Scale during the Operation}

Scale piles up on the bottom of the soaking zone and the lower heating zone. In the soaking zone the materials pile up on the scale and in the lower heating zone the available combustion space becomes smaller. The gas flow patterns are shown in Fig. 7 for these cases. This piling up generally has a small effect on the gas flow patterns because the burner setting has been so arranged.

\section{Summary}

The model experiments were made to investigate the proper design for the reconstruction of a three-zone pusher furnace. They showed the best way of reconstruction concerning the furnace shape and the burner setting. The final arrangement recommended is shown in Photo. 1 and Fig. 8. In each experiment the factors were changed one by one. Interrelated effects due to the changes were found to be negligibly small.

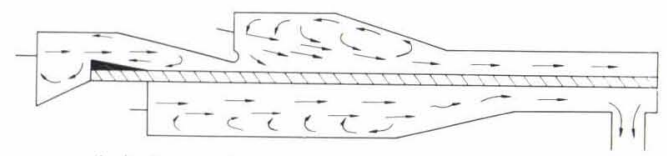

(a) In soaking zone

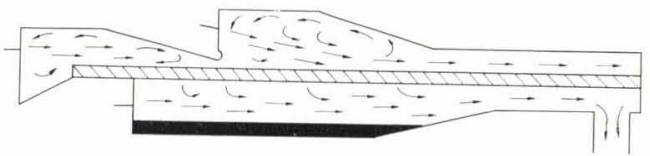

(b) In lower heating zone

Fig. 7. Gas flow patterns when scales are piled up. (Section of burner axis)
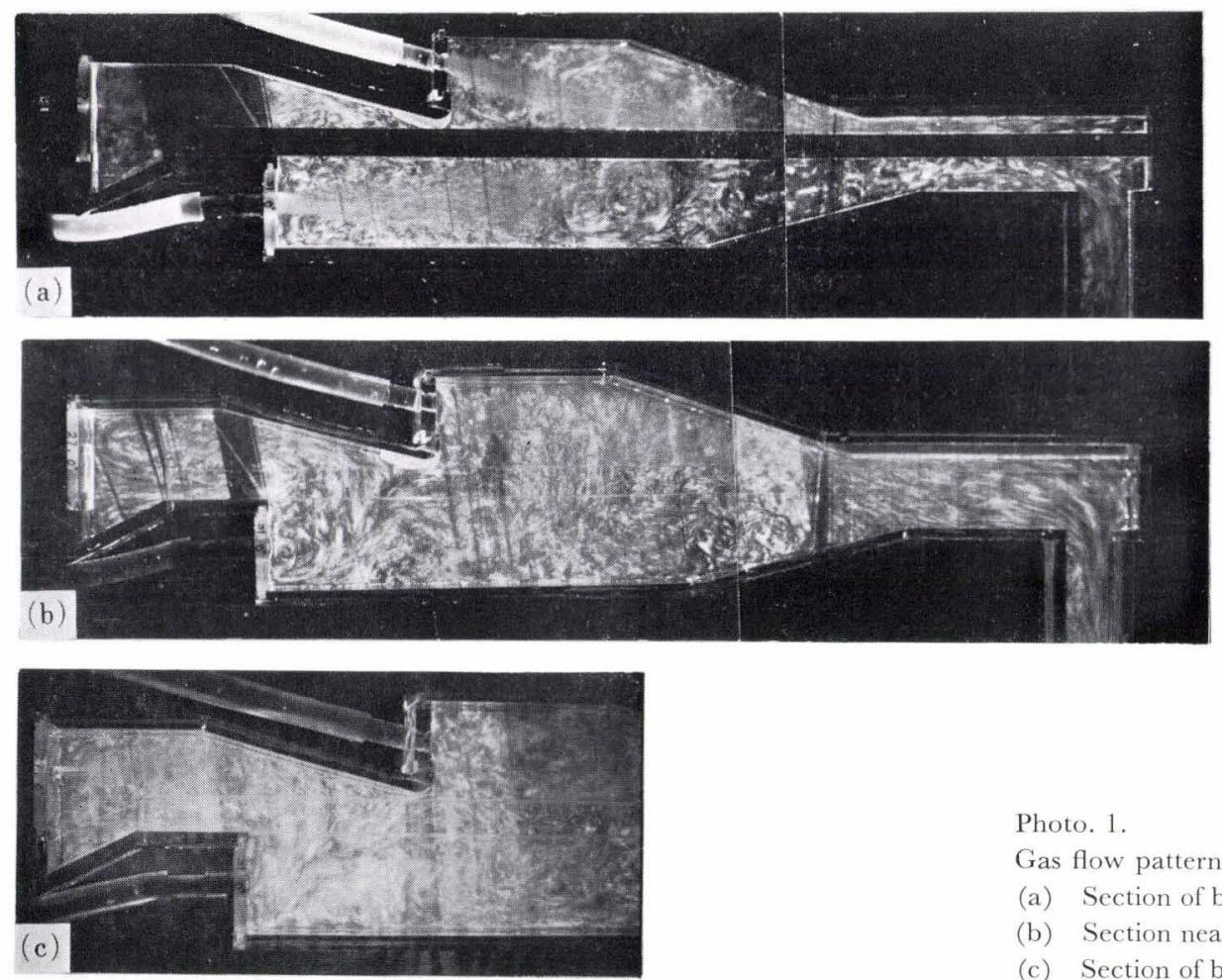

Photo. 1.

Gas flow pattern in the furnace after reconstruction

(a) Section of burner axis

(b) Section near the wall

(c) Section of burner axis in the soaking zone 
Furnace statistics are shown in Figs. 9 and 10, which show the relation between the heating capacity and the characteristic dimensions of the furnace. These data are only concerned with reheating furnaces whose characteristics are published in Japan. ${ }^{21)}$

Figure 9 shows the relation between the heating capacity and the effective furnace length. Figure 10 shows the relation between the heating capacity and the combustion space. These characteristics have a strong correlation with each other. The furnace under investigation is shown by solid circles. The effective furnace length is short comparing with $\mathrm{t} / \mathrm{hr}$ but the combustion space is slightly larger than the average. This is because the material heated in this furnace is extremely thick.

After the reconstruction the combustion space was increased by $18 \%$ and the heating capacity has increased by 12 to $20 \%$ (average $16 \%$ ) as is shown in Table 1 and the furnace is working satisfactorily.

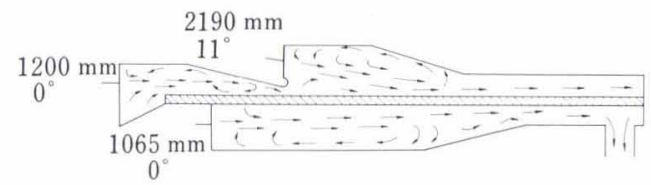

Fig. 8. Gas flow patterns in the furnace after reconstruction. (Section of burner axis)

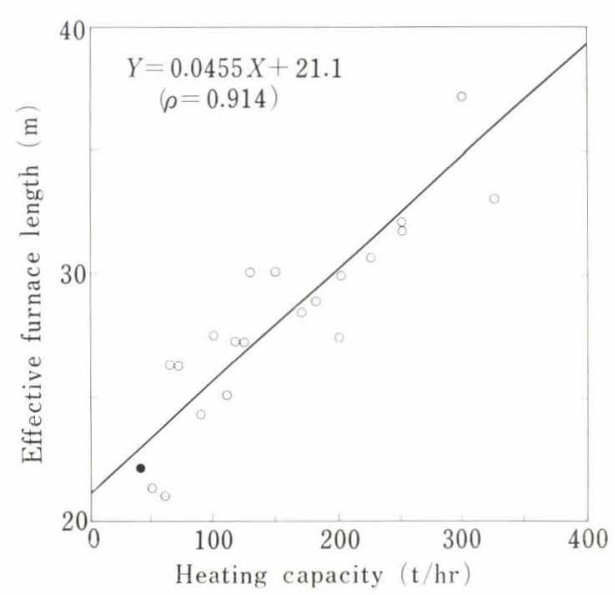

Fig. 9. Relation between effective furnace length and heating capacity

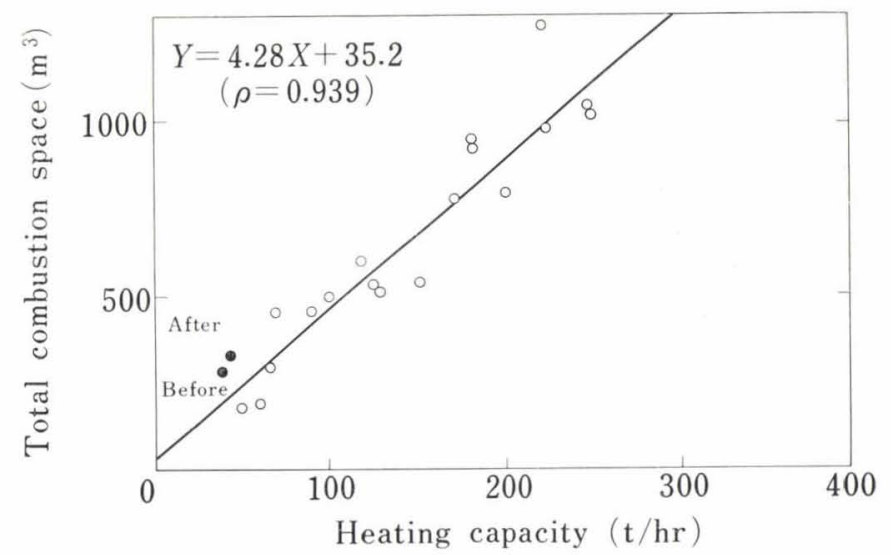

Fig. 10. Relation between total combustion space and heating capacity

\section{Conclusion}

Analysis based on a model is very useful for designing new plants or reconstructing existing ones. And it is also applicable for the operation of the system. There are many problems to be solved relating to combustion furnaces such as soaking pits, reheating furnaces or heat treatment furnace. In industry it is very important to increase the capacity of the equipment, to control the temperature distribution and to decrease the fuel consumption. Recently owing to the development of digital computer, mathematical models are also capable of being used for the analysis of heat transfer and the results indicate better operation conditions. Thus the model is a really effective analyzing technique and one of the particular applications has been shown in this paper.

\section{Acknowledgements}

At last but not at least the author wishes to thank Sumitomo Metal Ind., Ltd. for permission to publish this work and Dr. C. Hulse (Dept. of Fuel Tech. \& Chem. Eng., the University of Sheffield) and Dr. T. Tanoue (Central Research Labs., Sumitomo Metal Ind., Ltd.) for their helpful suggestions.

The list of references is not exhaustive.

\section{REFERENCES}

1) Nakamura: Mokeiriron to Scale up, (1954), Nikkan-Kogyo. Y. Yoshitani: Fuji-Seitetsu Gihou, 12 (1963), No. 1, 3.

R. E. Johnstone and M. W. Thring: Pilot Plant, Models, and Scale up Methods in Chemical Engineering, (1957), McGraw-Hill.

2) M. W. Thring: The Science of Flames and Furnaces, (1962), Chapman \& Hall.

J. M. Beer: J. Inst. Fuel, 39 (1966), No. 310, 466.

D. B. Spalding: 9th Symp. (International) on Combustion, (1963), 833, Academic Press.

3) R. Jeschar: Stahl u. Eisen, 8 (1968), No. 21, 1144.

4) Hashimoto: Netsu-Kanri, 9 (1957), No. 4, 19.

5) F. Fitzgerald and A. D. Robertson: J. Inst. Fuel, 40 (1967), No. $312,7$.

6) K. Okabe, Hamada, and Yonetani: Kawasaki-Seitetsu-Gihou, 44. (1969), No. 2, 160.

7) E. E. Hofman and A. Kappelmayer: Arch. Eisenhüttenw., 40 (1969), No. 4, 311.

8) H. Boenecke: Radex Rund., (1966), No. 8, 218.

9) Yoshida and Ishibashi: Seitetsu-Kenkyu, (1962), No. 240, 3845.

10) Hashimoto: Tetsu-to-Hagané, 42 (1956), 950, etc. Shimada et al.: Seitelsu-Kenkyu, (1964), No. 246, 4707: No. 247, 4937.

Tanoue, Tanaka and Hiraoka: Sumitomo-Kinzoku, 15 (1963), No. 4,240

J. H. Chester et al.: JISI, 162 (1949), No. 4, 385.

11) H. Boeneche and M. Hansen: Stahl u. Eisen, 87 (1967), No. 16, 951.

B. S. Holmes and M. W. Thring: JISI, 196 (1960), No. 11, 259.

12) Tanoue, Akamatsu, Nihonyanagi, and Ikeda: Tetsu-toHagané, 54 (1968), S 97.

13) Honma et al.: Tetsu-to-Hagané, 50 (1964), 398.

14) Saito, Kawai, and Tsu: Tetsu-to-Hagané, 47 (1961), 1382.

15) Tanoue, Hiraoka, and Nihonyanagi: Tetsu-to-Hagané, 51 (1965), 893.

16) J. H. Richa:d et al.: JISI, 197 (1961), No. 2, 117. 
17) H. Boenecke: Stahl u. Eisen, 82 (1962), No. 15, 1009. H. Boenecke: JISI, 197 (1961), No. 4, 283.

H. Boenecke: Iron Steel, (U.K.) 33 (1960), No. 14, 630.

18) M. A. Glinkov et al.: Stal', (1961), No. 1, 82

H. Boenecke: Arch. Eisenhüttenw., 32 (1961), No. 5, 317.
M. M. Korotaev: JISI, 199 (1961), No. 9, 15.

19) L. Hartwig: Stahl u. Eisen, 88 (1968), No. 23, 1302.

20) Taneda: Nihon Butsuri-Gakkaishi, 23 (1968), No. 6, 430.

21) Tekko-Kyodo-Kenkyu-Kai, Netsu-Keizai-Gijutsu-Bukai, 3rd Kanetsuro-Shoiinkai (1969, 7, 15). 